\title{
Algılanan Örgütsel Adaletin Örgütsel Vatandaşlık Davranışı Üzerindeki Etkisi: Otel Çalışanları Üzerine Bir Araştırma (The Effect of Perceived Organizational Justice on Organizational Citizenship Behavior: A Research on Hotel Employees)
}

\section{Yasin KELEŞ}

a Ondokuz Mayıs Üniversitesi, Turizm Fakültesi, Samsun, Türkiye. yasin.keles@omu.edu.tr

\begin{tabular}{|c|c|}
\hline MAKALE BİLGİSİ & ÖZET \\
\hline $\begin{array}{l}\text { Gönderme Tarihi } 15 \text { Eylül } 2018 \\
\text { Revizyon Tarihi } 28 \text { Şubat } 2019 \\
\text { Kabul Tarihi } 18 \text { Mart } 2019\end{array}$ & 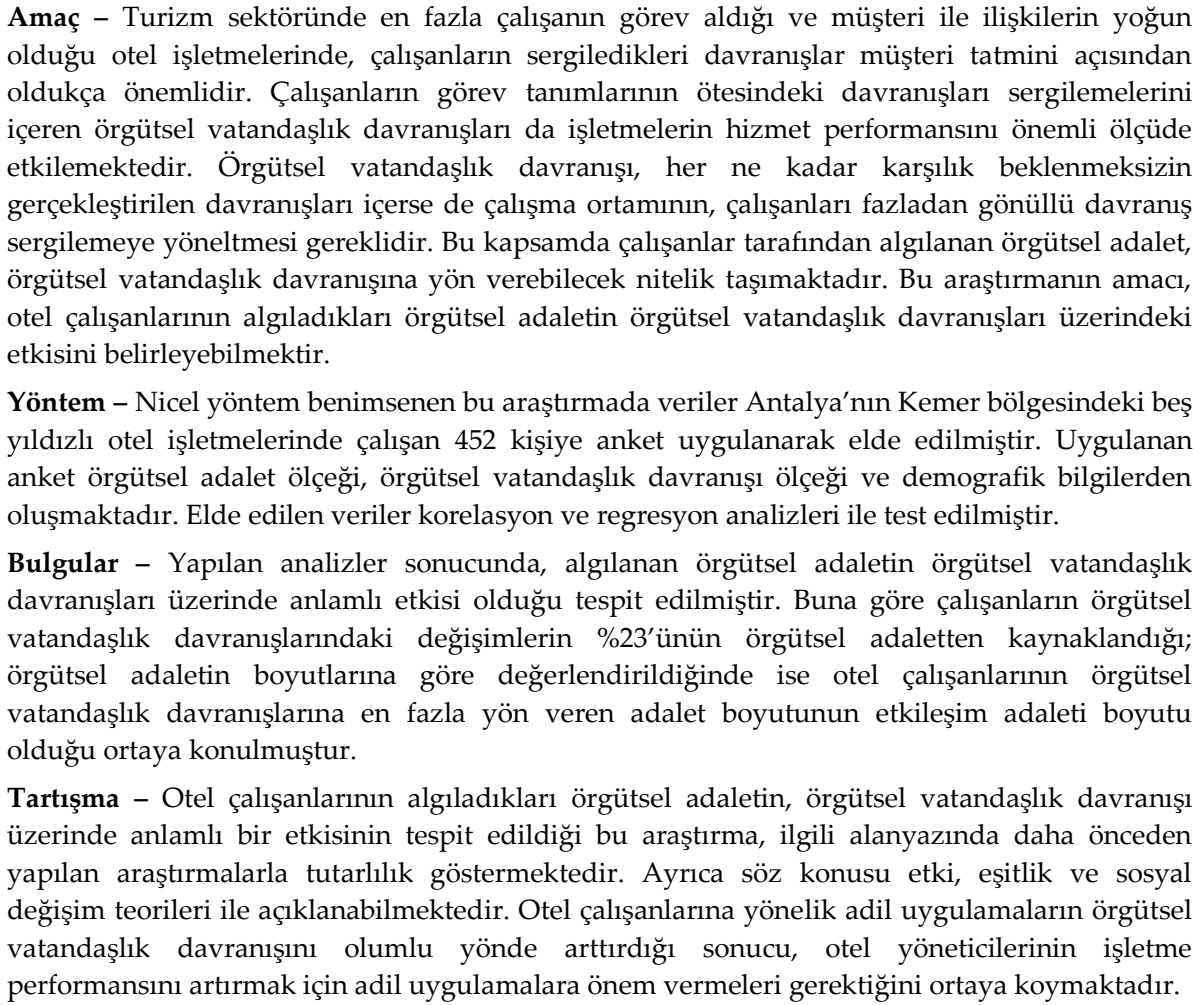 \\
\hline
\end{tabular}

\begin{tabular}{l}
\hline ARTICLE INFO \\
\hline Keywords: \\
Organizational Justice \\
Organizational Citizenship \\
Behavior \\
Tourism \\
Hotel employees
\end{tabular}

Received 15 September 2018

Revised 28 February 2019

Accepted 18 March 2019

\section{Article Classification:}

\section{ABSTRACT}

Purpose - In the hotel business where the highest number of employees is involved in the tourism sector and the relations with the customer are intense, the behaviors of the employees are very important in terms of customer satisfaction. Organizational citizenship behaviors, which include the behavior of employees beyond their job descriptions, significantly affect the service performance of the enterprises. Organizational citizenship behavior, although it includes the behaviors performed without anticipation, organizational circumstances should lead the employees to exhibit extra voluntary behavior. In this context, the organizational justice perceived by the employees may lead to organizational citizenship behavior. The purpose of this study is to determine the impact of the perceived organizational justice on the organizational citizenship behaviors of hotel employees.

Design/methodology/approach - In this study, the quantitative method was used and the data were obtained by applying a questionnaire to 452 people working in five star hotels in Kemer, Antalya. The questionnaire consisted of organizational justice scale, organizational citizenship behavior scale and demographic information. The obtained data were tested by correlation and regression analysis.

Results - As a result of the analysis, it was found that organizational justice had a significant effect on organizational citizenship behaviors. According to this, $23 \%$ of the employees' 

according to the dimensions of organizational justice, it was revealed that the justice dimension which has the strongest effect on the organizational citizenship behaviors of hotel employees is the interaction justice.

Discussion - This study, in which a significant effect of the organizational justice perceived by the hotel employees on organizational citizenship behavior is determined, is consistent with the previous studies in the relevant literature. This effect can also be explained by the Equality and Social Change theories. The fact that fair practices for hotel employees positively increase the behavior of organizational citizenship reveals that hotel managers should pay attention to fair practices to improve business performance.

\section{GíRiş}

Kelime anlamı incelendiğinde, hak ve hukuka uygunluk, hakkı gözetme şeklinde tanımlanan (TDK, 2019) adalet kavramı, çalışma yaşamının en önemli konuları arasında yer almaktadır. Her gün işyerine giden çalışanların, farkında bile olmadan, adalet arayışı içinde olacaktır. Çalışanların örgüte karşı davranışlarının şekillenmesinde örgütsel adaletin etkili olduğu ifade edilmektedir (Lambert, 2003:155). Örgüte yönelik algılanan adalet sonucunda çalışanlarda oluşan olumlu ya da olumsuz duygular, yaptıkları işin niteliğine yansiyacaktır.

Örgütsel adalet ile ilgili yapılan araştırmalar, adil algılamaları olan çalışanların, örgüte yönelik olumlu eğilimlerinin oluşacağının yanı sıra örgütün yararına davranışlar sergileyeceğine vurgu yapmaktadır (Barling ve Michelle, 1993:649; Keleş ve Tuna, 2016:377-378). Özellikle müşteri ile ilişkilerin yüz yüze ve yoğun olduğu turizm sektörü açısından konuya bakıldığında, algılanan adaletin çalışanların hizmet süreçlerine yansıması kaçınılmazdır. Turizmin en fazla insanın çalıştı̆̆ı sektörü olan otelcilikte, çalışanların birbirlerine olan yardımları, davranışları bunun yanında dayanışmaları, hizmetin kalitesine önemli ölçüde etki edebilecek kadar hassasiyet içermektedir. Aynı zamanda anlık olarak gelişen sorunlara çözüm üretilmesi, örgütün geleceğini ve işleyişini ilgilendiren durumlarda kararlara katılma ve sorumluluk alma eğilimi de algılanan adalet ile ilişkili konular olarak değerlendirilebilir. Yapılan araştırmalar, algılanan örgütsel adaletin iş tatmini, örgütsel bağl1lık ve örgütsel güven gibi örgüt açısından önemli sonuçları olan hususlara yön verdiğini göstermektedir (Albrecht ve Travaglion, 2003; Aryee vd., 2002; Ay ve Koç, 2014; Begley vd., 2006; Brashear vd., 2004; Camerman vd., 2007; Choi, 2011; DeConinck, 2010; Folger ve Konovsky, 1989; Hon ve Lu, 2010; Hubbell ve Chory-Assad, 2005; Lambert, 2003; Lowe ve Vodanowich, 1995; Martin ve Bennett, 1996; McFarlin ve Sweeney; 1992, Moorman vd.,1993; Tang ve Baldwin, 1996; Taxman ve Gordon, 2009; Pillai vd., 1999; Yang vd., 2009).

Bireylerin iş ortamındaki davranışlarını şekillendiren önemli bir unsur olan örgütsel adaletin, çalışanların biçimsel rollerinin ötesine geçerek fazladan sergiledikleri davranışları ifade eden örgütsel vatandaşlık davranışları (Organ, 1988:4) üzerindeki etkisi de alanyazında üzerinde çalışılan araştırma alanlarından biridir. Daha önce de ifade edildiği üzere otelcilik sektörünün yapısından kaynaklanan sebepler, söz konusu bu etkinin önemini arttırmaktadır. Hizmetin üretildiği anda tüketilmesi, iş anında ortaya çıkabilecek olumsuzlukların tüketiciye yansımasını da beraberinde getirecektir. İş yerinde biçimsel rol tanımlarının ötesindeki davranışları içeren örgütsel vatandaşlık davranışının sergilenme sıklığı, ortaya çıkabilecek sorunları en aza indirecektir. Bu yüzden örgütsel vatandaşlık davranışının örgütsel adaletin hangi boyutlarından ne düzeyde etkili olduğunun ortaya konulması, gerek ilgili alanyazına gerekse doğrudan çalışma yaşamına katkı sağlayacak sonuçlara ulaştırabilir. Bu araştırmada otel çalışanlarının algıladıkları örgütsel adaletin örgütsel vatandaşlık davranışı üzerindeki etkisi incelenmiştir.

\section{1. Örgütsel Adalet}

Örgütsel adaletin kaynağı, Adams'ın eşitlik teorisine dayanmaktadır. Adams (1965:283-295), eşitsizlik durumunda çalışanların kazançlarını ve işe karşı yatırımlarını bilinçli veya bilinçsiz olarak değiştirmesi, bulundukları ortamdan ayrılması ve karşılaştırdıkları kişiyi değiştirmesi gibi tepkiler geliştirdiklerini ifade etmektedir. Buna göre çalışanların, iş ortamında algıladıkları adalete göre, davranışlarını şekillendirebileceği sonucu ortaya çıkmaktadır. Moorman (1991:845), örgütsel adaleti, çalışanların işlerinde kendilerine adil davranılıp davranılmadığına nasıl karar verdikleriyle ve bu kararların işle ilgili diğer değişkenleri nasıl etkilediğiyle ilgili bir kavram olduğunu ifade etmektedir. Çalışanların adalet algılamaları, görev 
paylaşımları, kazanımlar, süreçlerin işleyişi ve yöneticilerin ilişkilerinin niteliği gibi faktörler ile şekillenmektedir. Bu durumda örgütsel adaletin boyutlarını incelemekte fayda vardır.

Örgütsel adalet, bazı araştırmacılar tarafından dağıtım adaleti ve işlem adaleti olmak üzere iki boyutta ele alınmıştır (Folger ve Konovsky, 1989; Greenberg, 1990; Lee ve Farh, 1999). Bu araştırmalarda işlem adaleti kapsamında değerlendirilen etkileşim adaleti, birçok araştırmada dağıtım ve işlem adaletine ek olarak başka bir boyut olarak ele alınmıştır (Aryee vd. 2002; Bies, 2001; Cropanzano vd. 2001; Greenberg, 2004; Moorman, 1991; Olkonen ve Lipponen, 2006; Scandura, 1999; Skarlicki vd., 1999; VanYperen vd., 2000).

Dağıtım adaleti, çalışanların elde ettikleri kazanımlar ile hak ettiklerine inandıkları kazanımlar arasında yaptıkları kıyaslamaya ilişkin algılamalarını ifade etmektedir (Skarlicki ve Folger, 1997: 435;). Dağıtım adaleti görevler, hizmetler, fırsatlar, cezalar/ ödüller, roller, statüler, ücretler, terfiler, vb. her türlü kazanımın kişiler arasındaki paylaşımını konu alan bir kavram olmakla birlikte bu kaynakların işletme çalışanlarına eşit olarak paylaştırılması şeklinde değerlendirilmektedir (Cohen, 1987:19-20). Alexander ve Ruderman (1987:177), adaletsiz dağıtımın, çalışanların performanslarının düşmesine, diğer çalışanlarla daha az iş birliğine gitmelerine ve verimsiz davranışlar sergilemelerine neden olduğuna vurgu yapmaktadır.

İşlem adaleti, çalışma koşullarına yönelik olarak alınan kararlarda izlenen strateji ve politikaların adil olma derecesi ile ilişkilidir (Jahangir vd., 2006:23). Basit olarak örgüt tarafından kararların alınmasında kullanılan süreçlere ilişkin adalet algılamaları olarak tanımlanan işlem adaleti (prosedür adaleti) (Scandura, 1999:26), kazanımların neye göre ve nasıl belirlendiğini, kazanımların dağıtımında kullanılan karar verme mekanizmasının nasıl işlediğini ve bu mekanizmanın çalışanlarca ne kadar adil algılandığını (Konovsky, 2000:489) açıklamaktadır. Tyler (1988:103), çalışanların örgütsel adalet algılamalarını en çok etkileyen adalet boyutunun işlem adaleti olduğunu ifade etmektedir. Dağıtım ve işlem adaleti bireylerin işe ve örgütlerine karşı olan tutumlarını etkilerken, etkileşim adaleti ise yöneticilerine karşı olan tutumlarını etkilemektedir (Masterson vd., 2000:744).

Etkileşim adaleti, örgütsel adaletin insani yönü ile ilgilidir (Kwak, 2006:10). Bies (2001:100-101), etkileşim adaletini, örgütsel prosedürler uygulanırken bireylerin karşılaştığı tutum ve davranışların biçimi olarak tanımlanmıştır. Cropanzano ve Greenberg (1997:317), etkileşim adaletinin kişilerarası ilişkilerin kalitesi ile ilgili olduğunu ve işlem adaletinin sosyal bir boyutu olduğunu öne sürmektedir. Özet olarak etkileşim adaletinin, bireyler arası ilişkilere yapılan yatırımlar ve bu ilişkilerden elde edilebilecek çıtılar üzerine odaklandığ1 söylenebilir (Ramamoorthy ve Flood, 2004:249). Cropanzano ve Wright (2003:10), bireylerin istenmeyen bir sonuçla ilgili kendilerine yeterli bir açıklama yapıldığında daha toleranslı olabildiğini ifade etmektedir. Bunun tersi durumda ise algıladıkları adaletsiz etkileşimden dolayı, çalışanlar bütün örgüte veya kendi çıktılarına değil, yöneticilerine karşı tepki göstermeye yönelmektedirler (Crpanzano ve Wright, 2003:200).

\section{2. Örgütsel Vatandaşlık Davranışı}

Temeli Organ ve arkadaşları tarafından yapılan çalışmalara (Bateman ve Organ, 1983; Smith vd., 1983; Organ, 1988) dayanan örgütsel vatandaşlık davranışı, çalışma ortamında belirlenen standartların ve iş tanımlarının ötesinde bireylerin sergilediği gönüllü veya fazladan rol davranışı olarak tanımlanmaktadır (Organ, 1988:4). Greenberg ve Baron (2000:212) örgütsel vatandaşlık davranışını, çalışanların örgüt tarafından belirlenen biçimsel rollerin ötesine geçerek, istenenden daha fazlasını yapması olarak açıklamaktadır. Örgütsel vatandaşlık davranışı, iş/örgüt için fazladan sergilendiği için yararlı davranışlar olarak değerlendirilmektedir (Dick vd., 2008:391). Tanımlardan da anlaşılacağı üzere, örgütsel vatandaşlık davranışı gönüllülük esasına dayandığından, örgütün ödül sistemi ile ilişkili olmayıp karşılık beklemeden sergilenen davranışlardır (Deluga, 1995:1-2). Aynı zamanda örgütsel vatandaşlık davranışı, beklenmeyen olaylarda, çalışanlar arasında dayanışma sağlamaktadır (Smith vd., 1983:653-654).

Örgütsel vatandaşlık davranışı, ilgili alanyazında (Organ ve Konovsky, 1989; Farh vd., 1990; Moorman, 1991; Moorman, vd., 1993; Tansky, 1993; Deluga, 1995) özgecilik, vicdanlılık, nezaket, centilmenlik ve üyelik erdemi (sivil erdem) olmak üzere beş boyutta ele alınmaktadır. Özgecilik, işle ilgili sorunların ortaya çıkan sorunları engellemek amacıyla diğer çalışanlara yardım etmeyi içeren davranışlardır (Organ ve Konovsky, 1989:157; Podsakoff vd., 2000:516). Vicdanlılık, çalışanların kendilerinden beklenenlerden fazla olarak gönüllü bir biçimde ortaya koydukları fazladan davranışları sergilemeyi içermektedir (Barkslade ve Werner, 
2001:148; Schnake ve Dumler, 2003:284). Örneğin, mesai saati dolduğu halde işi bitmeyen çalışanın, saati dikkate almaksızın işini bitirdikten sonra iş yerinden ayrılması ve bu davranıştan dolayı herhangi bir beklenti içinde olmaması, vicdanlılık davranışı kapsamında değerlendirilebilir. Nezaket boyutu özgecilik boyutu ile karıştırılmakla birlikte, özellikle diğer çalışanlarla ilgili olası problemleri önceden görebilmeye ve ortaya çıkabilecek problemlerin önüne geçebilmeye yönelik bireyler arasındaki olumlu iletişime dayanan davranışlara odaklanmaktadır (Konovsky ve Organ, 1996:255). Çalışma arkadaşlarının hakkını koruma, sorun çıkmadan önce sorunu öngörerek yapıcı tutum sergileme gibi davranışlar, nezaket davranışlarına örnek gösterilebilir. Centilmenlik, örgütte bireylerarası ilişkilerde ortaya çıkabilecek küçük problemleri büyütmeme, şikâyet etmeden giderme; başka bir ifade ile gerginliğe neden olabilecek durumlardan kaçınma davranışlarını içeren boyuttur (Konovsky ve Organ, 1996:255; Podsakoff vd., 2000:518; Schnake ve Dumler, 2003:284). Son olarak üyelik erdemi boyutu ise örgüt içinde düşünceyi ifade etmeyi (Kidder, 2002:637) ve örgüte aktif ve gönüllü olarak katılmayı (Podsakoff ve MacKenzie, 1994:351), başka bir ifade ile örgüt yaşamıyla ilgili sorumluluk almayı, ifade etmektedir (Podsakoff vd., 1997:263).

Örgütsel vatandaşlık davranışının boyutları genel olarak değerlendirildiğinde, çalışanların birbirine yardımını, dayanışmasını, örgüt amaçlarına odaklanmayı, sorun ve gerginliklerden kaçınmayı ve örgütün geleceği için fikirleri ifade etmeyi içeren olumlu davranışlar bütününü oluşturmaktadır. Yapılan araştırmalar (Bateman ve Organ, 1983; Moorman vd., 1993; Williams ve Anderson, 1991; Borman ve Motowidlo, 1997), örgütsel vatandaşlık davranışı sergileyen çalışanların performanslarının, diğerlerine nazaran daha yüksek olduğuna işaret etmektedir. Örgütsel vatandaşlık davranışı, daha önce de ifade edildiği üzere ödül sistemi ile ilişkili olmasa da gerçekleştirilen davranış takdir edildiğinde tekrarlanma eğilimi artacaktır (Miles vd., 2002:52). Özellikle müşteri ile yüz yüze iletişimin yoğun olduğu otel işletmelerinde, hizmet sırasında ortaya çıkabilecek olumsuz durumların müşteriye yansıma riski oldukça yüksektir. Örgütsel vatandaşlık davranışı sergileme eğilimin yüksek olduğu işletmelerde, bu riskin azalma eğilimi muhtemeldir. Bu yüzden örgüt yönetimlerinin örgütsel vatandaşlık davranışını arttıracak çalışma şartları oluşturması, örgüt yararına olacaktır.

\section{3. Örgütsel Adaletin Örgütsel Vatandaşlık Davranışı Üzerindeki Etkisi}

Örgütsel vatandaşlık davranışının, iş tatmini (Cropanzano vd., 2003; Motowidlo, 2000; Tansky, 1993), örgütsel bağlılık (Cohen, 2006; Motowidlo, 2000) lider davranışları (Bateman ve Organ, 1983:588; Farh vd.,1990 ; Podsakoff vd., 1990), işin ve örgütün özellikleri (Somech ve Ron, 2007; Van Dyne vd., 1994) ile ilişkili olduğu yönünde araştırma sonuçları ile karşılaşmak mümkündür. İlgili çalışmalar genel olarak değerlendirildiğinde; çalışma koşullarından ve görevinden, yöneticilerinin davranışlarından memnun olan, çalıştığı işletmeye karşı olumlu duyguları oluşan ve işinden keyif alan bireylerin örgütsel vatandaşlık davranışı sergileme eğilimi arttığı sonucu çıkarılabilir. Buna göre, çalışanlar için önemli bir unsur olan örgütsel adaletin, sergileyecekleri örgütsel vatandaşlık davranışı üzerinde etkili olması beklenmektedir.

Bununla birlikte ilgili alanyazında örgütsel adaletin örgütsel vatandaşlık davranışını artırdığına yönelik sonuçlara ulaşılan fazlaca araştırma bulunmaktadır (Blakely vd., 2005; Chan ve Lai, 2017; Chou vd., 2013; Deluga, 1995; Eskew, 1993; Farh vd., 1990; Greenberg, 1993; İşbaşı, 2000; Kim vd., 2009; Lim ve Loosemore, 2017; Moorman, 1991; Moorman vd., 1998; Niehoff ve Moorman, 1993; Olkonnen ve Lipponen, 2005; Organ, 1988; Organ ve Konovsky, 1989; Özduran ve Tanova, 2017; Schappe, 1998; Smith vd., 1983; Tansky; 1993).

Örgütsel adaletin örgütsel vatandaşlık davranışı üzerindeki etkisini sosyal değişim ve eşitlik kuramları ile de açıklamak mümkündür. Sosyal değişim kuramına göre, ekonomik beklentilere odaklanmadan yalnızca iş arkadaşının beğeni ve teşekkürüne odaklanan yardım etme davranışının geliştiği belirtilmektedir (Homans, 1958:605-606). Yine Blau (1964:8), sosyal değişimi maddi kazanç amacı güdülen ekonomik değişimden ayırt etmiştir. Buna göre, görev tanımlarının ötesindeki örgütsel vatandaşlık davranışını açıklarken, adil bir iş ortamının sosyal değişime ve sonuç olarak örgütsel vatandaşlık davranışına yön vereceğini ifade etmek mümkün olacaktır. Sosyal değişime ilişkin olumsuz algılamalara sahip olan çalışanlar, örgüt yararına olmayan davranışlara yönelebilmektedir (Pelit ve Bozdoğan, 2014). Bu durum da örgütsel vatandaşlık davranışının sergilenmeyeceği sonucu çıkarılabilir.

Örgütsel adalet ve örgütsel vatandaşlık davranışı ilişkisini açıklayan diğer bir kuram ise Adams (1965)'ın eşitlik kuramı olarak değerlendirilebilir. Adams (1965)'a göre, çalışanlar görev ve ödül paylaşımı ile iş ilişkilerinde eşit bir yaklaşım görmek ve çabalarının karşılığını almak istemektedirler. Aksine, 
kazanımlarının fazla ya da az olduğunu düşünen çalışan, adaleti sağlamak için, işletmeye olan katkılarını azaltmaya veya arttırmaya gidebilecektir. İşletmeye olan katkıları arttırmak, daha fazla çalışmak, sorunların önüne geçmek, sorumluluk almak ve iş arkadaşlarına yardım etmek şeklinde gelişebilir. Bu davranışlar ise örgütsel vatandaşlık davranışına örnek teşkil etmektedir. Turizm ve/veya otelcilik sektöründeki çalışma koşulları ve ilişkileri dikkate alındığında, sosyal değişim ve eşitlik kuramlarının çalışan davranışları açısından ne denli önemli olduğunu ifade etmek yerinde olacaktır.

Otel çalışanları, sektörün emek yoğun özelliğinden dolayı birçok standart uygulamayı hatasız ve eksiksiz yerine getirmek ve böylelikle müşteri memnuniyetini işletme adına sağlamak durumundadırlar. Bu yüzden yardımlaşmayı, oluşabilecek sorunları en aza indirmeyi ve örgüt yararına olacak davranışlar sergilemeyi kapsayan örgütsel vatandaşlık davranışı, otelcilik/turizm sektörü için oldukça önemlidir. Hatta iş tatmini, örgütsel bağllık ve yüksek performans ile ilişkili olan örgütsel vatandaşlık davranışının turizm işletmeleri için hayati bir öneme sahip olduğu (Keleş ve Pelit, 2009; Özduran ve Tanova, 2017) ifade edilmektedir. Bu yüzden otel çalışanlarının sergiledikleri örgütsel vatandaşlık davranışının, ödül ve görevlerin, örgütsel süreçlerin ve yönetici-çalışan arsındaki ilişkinin adilliğini ifade eden örgütsel adalet ile ilişkisi kaçınılmazdır. $\mathrm{Bu}$ araştırmanın amacı, otel işletmelerinde çalışanların algıladıkları örgütsel adaletin örgütsel vatandaşlık davranışları üzerindeki etkisini belirleyebilmektir. Bu kapsamda araştırmanın hipotezleri şu şekilde geliştirilmiştir:

Hı: Otel çalışanların algıladıkları dağıtım adaletinin örgütsel vatandaşlık davranışları üzerinde anlamlı bir etkisi vardır.

$\mathrm{H}_{2}$ : Otel çalışanların algıladıkları işlem adaletinin örgütsel vatandaşlık davranışları üzerinde anlamlı bir etkisi vardır.

H3: Otel çalışanların algıladıkları etkileşim adaletinin örgütsel vatandaşlık davranışları üzerinde anlamlı bir etkisi vardır

$\mathrm{H}_{4}$ : Otel çalışanların algıladıkları örgütsel adaletin örgütsel vatandaşlık davranışları üzerinde anlamlı bir etkisi vardır

Araştırmanın devam eden bölümünde, yönteme, bulgulara ve araştırma sonuçlarına yer verilmiştir.

\section{YÖNTEM}

Nicel yöntem benimsenen ve betimsel nitelik taşıyan bu araştırmada veriler, anket aracılığıyla toplanmıştır. Anket, örgütsel adalet ve örgütsel vatandaşlık davranışı ölçekleri ile demografik soruları kapsamaktadır. Temeli Moorman (1991)'ın çalışmasına dayanan ve Niehoff ve Moorman (1993) tarafından kullanılan örgütsel adalet ölçeği; dağıtım, işlem ve etkileşim adaleti olmak üzere 3 boyutu içeren 20 ifadeden oluşmaktadır. Söz konusu ölçek Yıldırım (2003) tarafından Türkçeye uyarlanmıştır. Araştırmaya katılanların örgütsel vatandaşlık davranışı ise Basım ve Şeşen'in (2006)'in Vey ve Campbell (2004) ile Williams ve Shiaw (1999)'ın ölçeklerinden yararlanarak Türkçeye uyarladığı, özgecilik, vicdanlılık, nezaket, centilmenlik ve üyelik erdemi olmak üzere 5 boyuttan ve 19 ifadeden oluşan ölçek ile tespit edilmiştir.

Araştırmanın evreninin Antalya'nın Kemer bölgesindeki 5 yıldızlı otel işletmelerinde çalışanlar oluşturmaktadır. Kemer Bölgesi'ndeki otel ve çalışan sayısının fazlalı̆̆ı nedeniyle, örneklem alma yoluna gidilmiştir. Buna göre uygun (kazara) örnekleme yöntemi ile seçilen 9 oteldeki çalışanlar için sunulan 600 adet anketten geri dönen ve geçerli olan 452 anket formu dikkate alınmıştır. Geçerliliği ilgili alanyazında kanıtlanan ölçeklerin ve alt boyutlarının güvenilirlik katsayıları kabul edilebilir en az değerlerin üzerinde olup güvenilir bulunmuştur. Katılımcıların örgütsel adalet ve örgütsel vatandaşlık davranışı ölçeklerindeki ifadelere ilişkin cevaplarının ortalama ve standart sapma değerlerine yer verilmiş olup örgütsel adaletin örgütsel vatandaşlık davranışı üzerindeki etkisi ise korelasyon ve regresyon analizleri ile test edilmiştir. Katılımcıların demografik özellikleri yüzde ve frekans analizi ile betimlenmiş ve Tablo 1'de yer sunulmuştur:

Tablo 1. Katılımcıların demografik özelliklerine ilişkin bilgileri 
Y. Keleş 11/1 (2019) 612-624

\begin{tabular}{|c|c|c|c|}
\hline Demografik değişkenler & & $\mathrm{f}$ & $\%$ \\
\hline \multirow{2}{*}{ Cinsiyet } & Kadın & 158 & 34,6 \\
\hline & Erkek & 298 & 65,4 \\
\hline \multirow{5}{*}{ Yaş grubu } & 20 yaş ve altı & 106 & 23,2 \\
\hline & $21-25$ yaş arası & 174 & 38,2 \\
\hline & $26-30$ yaş arası & 95 & 20,8 \\
\hline & $31-35$ yaş arası & 37 & 8,1 \\
\hline & 36 ve üzeri yaş & 44 & 9,6 \\
\hline \multirow{2}{*}{ Medeni durum } & Bekâr & 332 & 72,8 \\
\hline & Evli & 124 & 27,2 \\
\hline \multirow{3}{*}{ Eğitim durumu } & İlköğretim & 63 & 16,0 \\
\hline & Ortaöğretim (Lise) & 188 & 48,0 \\
\hline & Üniversite & 141 & 36,0 \\
\hline \multirow{4}{*}{ Çalışılan departman } & Önbüro & 59 & 12,9 \\
\hline & Yiyecek-İçecek & 260 & 57,0 \\
\hline & Kat Hizmetleri & 69 & 15,1 \\
\hline & Diğer & 68 & 14,9 \\
\hline \multirow{2}{*}{ İşletmede çalışma süresi } & $1-5$ y1l & 395 & 86,6 \\
\hline & 5 yildan fazla & 61 & 13,4 \\
\hline \multirow{3}{*}{ Sektörde çalışma süresi } & $1-5$ yıldır & 249 & 54,6 \\
\hline & $6-10$ yıldır & 144 & 31,6 \\
\hline & 11 yıl ve fazlası & 63 & 13,8 \\
\hline
\end{tabular}

Tablo1'de de görüldüğü gibi, araştırmada ankete cevap verenlerin çoğunluğu erkek $(\% 65,4)$ ve 25 yaş altındadır $(\% 61,4)$. Katılımcıların $\% 72$ 'si bekar olup \%36'sı üniversite, \%48'i ise lise mezunudur. Araştırmaya katılanların çoğunluğu 5 yıldan daha az süredir kendi işletmesinde $(\% 86,8)$ ve turizm sektöründe $(\% 54,6)$ çalışmaktadır. Buna göre aynı işletmede 5 yıldan fazla süredir çalışanların oranı yalnızca \%13,4 iken, turizm sektöründe çalışanların oranı ise $\% 13,8^{\prime}$ dir. 11 yıl ve daha az süredir turizm sektöründe çalışanlar, katılımcı grubunun $\% 87,2$ 'sini oluşturmaktadır.

\section{BULGULAR}

Araştırmanın bu bölümünde, öncelikle örgütsel adalet ve örgütsel vatandaşlık davranışı arasındaki ilişkiler korelasyon analizi ile sunulmuştur. Ayrıca, örgütsel adalet ve örgütsel vatandaşlık davranışının hem geneline hem de bütün alt boyutlarına ilişkin ortalama ve standart sapma değerlerine Tablo 2'de yer verilmiştir.

Tablo 2'de de görüldüğü gibi, araştırmaya katılanların örgütsel adalet algılamalarına ilişkin ortalama değeri 3,07'dir. Dağıtım adaleti 2,92 ortalama ile en düşük adalet algılanan boyut iken, etkileşim adaleti 3,15 ortalama değeri ile çalışanların en fazla adil olduklarını düşündükleri boyuttur.

Araştırmaya katılanların örgütsel vatandaşlık davranışlarına ilişkin ortalaması ise 3,64 olup orta değerin üzerindedir. Nezaket boyutu, 3,95 ortalama ile katılımcıların en fazla sergiledikleri örgütsel vatandaşlık davranışı boyutu olurken, üyelik erdemi boyutu 3,53 ortalama ile en az sergilenen örgütsel vatandaşlık davranışı boyutlarını oluşturmaktadır.

Tablo 2. Örgütsel adalet ve örgütsel vatandaşlık davranışı ilişkisine yönelik korelasyon matrisi ile ortalama ve standart sapama değerleri

\begin{tabular}{llllllllllll} 
Ort. & s.s. & 1 & 2 & 3 & 4 & 5 & 6 & 7 & 8 & 9 & 10 \\
\hline
\end{tabular}




\begin{tabular}{|c|c|c|c|c|c|c|c|c|c|c|c|c|c|}
\hline 1 & Dağıtım adaleti & 2,92 & 1,09 & - & & & & & & & & & \\
\hline 2 & İşlem adaleti & 3,07 & 1,14 & ,706 & - & & & & & & & & \\
\hline 3 & Etkileşim Adaleti & 3,15 & 1,10 & 689 & 833 & - & & & & & & & \\
\hline 4 & Özgecilik & 3,60 & 0,91 & $309^{* *}$ & $310^{* *}$ & $372^{* *}$ & - & & & & & & \\
\hline 5 & Vicdanlılık & 3,57 & 0,98 & $276^{* *}$ &, $315^{* *}$ &, $362^{* *}$ & ,546 & - & & & & & \\
\hline 6 & Nezaket & 3,95 & 1,03 & $246^{* *}$ & $259^{* *}$ &, $328^{* *}$ & 674 & ,546 & - & & & & \\
\hline 7 & Centilmenlik & 3,60 & 0,95 &, $331^{* *}$ & , 372** & $442^{* *}$ & 677 & ,544 & 644 & - & & & \\
\hline 8 & Üyelik erdemi & 3,53 & 1,01 & $444^{* *}$ & $420^{* *}$ & $473^{* *}$ & ,586 & ,561 & ,541 & ,630 & - & & \\
\hline 9 & Örgütsel Adalet & 3,07 & 1,02 & 840 & ,930 & ,951 & $368^{* *}$ & $356^{* *}$ & $312^{* *}$ & $428^{* *}$ & $490^{* *}$ & - & \\
\hline 10 & Örgütsel Vatandaşlık & 3,64 & 0,80 & ,396** &, $411^{* *}$ &, $484^{* *}$ & 866 & ,752 & 815 & 855 & 817 &, $479^{* *}$ & - \\
\hline
\end{tabular}

Tablo 2’ye göre, örgütsel adalet boyutları ile duygusal emek boyutları arasında pozitif yönlü anlamlı ilişkiler tespit edilmiştir. Buna göre, yapılan korelasyon analizi sonucunda örgütsel vatandaşlık davranışı ile örgütsel adaletin dağıtım adaleti boyutu $(\mathrm{r}=0,396)$, işlem adaleti boyutu $(\mathrm{r}=0,411)$ ve etkileşim adaleti boyutu arasında $(\mathrm{r}=0,484)$ orta kuvvette pozitif yönlü anlamlı ilişkiler tespit edilmiştir $(\mathrm{p}<0,001)$. Söz konusu katsayılar, örgütsel vatandaşlık davranışının en fazla örgütsel adaletin etkileşim adaleti boyutu ile ilişkili olduğunu göstermektedir. Örgütsel adalet bütün olarak korelasyon analizine alındığında, boyutlardaki ilişkilerde olduğu gibi, örgütsel adalet ile örgütsel vatandaşlık davranışı arasında orta kuvvete pozitif yönlü anlamlı bir ilişki tespit edilmiştir $(r=0,479)$. Söz konusu ilişkilerin yönünü, başka bir ifade ile çalışanların örgütsel vatandaşlık davranışlarındaki değişimlerin ne kadarlık kısmının örgütsel adaletten ve ayrı ayrı olarak örgütsel adalet alt boyutlarından kaynaklandığını belirleyebilmek amacıyla gerçekleştirilen basit doğrusal regresyon analizleri sonuçları Tablo 3, 4, 5 ve 6’ da sunulmuştur.

Tablo 3. Dağıtım adaletinin örgütsel vatandaşlık davranışı üzerindeki etkisine yönelik gerçekleştirilen basit doğrusal regresyon analizi

\begin{tabular}{llcccccc}
\hline $\begin{array}{l}\text { Bağımlı } \\
\text { Değişken }\end{array}$ & $\begin{array}{l}\text { Bağımsız } \\
\text { Değişken }\end{array}$ & $\mathbf{b}_{\mathbf{j}}$ & $\mathbf{S}\left(\mathbf{b}_{\mathbf{j}}\right)$ & $\mathbf{t}$ & $\mathbf{p}$ & $\mathbf{R}^{2}$ & ANOVA \\
\hline $\begin{array}{l}\text { Örgütsel Vatandaşlık } \\
\text { Davranışı }\end{array}$ & Sabit & 2,783 & 0,099 & 28,141 & $0,000^{* * *}$ & 0,157 & $\begin{array}{l}F=84,529 \\
\mathrm{p}=0,000^{* * *}\end{array}$ \\
\hline
\end{tabular}

$*{ }^{*} p<0,001 \quad b_{j}:$ Katsayı $S\left(b_{j}\right):$ Standart Hata

Tablo 3, örgütsel adaletin dağıtım adaleti boyutunun örgütsel vatandaşlık davranışı üzerindeki etkisine ilişkin gerçekleştirilen basit doğrusal regresyon modelinin anlamlı olduğunu göstermektedir ( $\mathrm{F}=84,529$; p<0,001). Söz konusu basit doğrusal regresyon modeli aşağ1da verilmiştir:

Örgütsel vatandaşlık davranışı = 2,783 +0,291 DA

Ayrıca Tablo 3'teki belirtme katsayısı $\left(\mathrm{R}^{2}=0,157\right)$ çalışanların örgütsel vatandaşlık davranışları üzerindeki değişimlerin \%15,7'sinin algıladıkları dağıtım adaletinden kaynaklandığı anlaşılmaktadır. Bu durumda; “ $H_{1}$ : Otel çalışanların algıladıkları dağıtım adaletinin örgütsel vatandaşlık davranışları üzerinde anlamlı bir etkisi vardır" hipotezi desteklenmiştir.

Tablo 4. İşlem adaletinin örgütsel vatandaşlık davranışı üzerindeki etkisine yönelik gerçekleştirilen basit doğrusal regresyon analizi

\begin{tabular}{llcccccc}
\hline Bağımlı & Bağımsız & $\mathbf{b}_{\mathbf{j}}$ & $\mathbf{S}\left(\mathbf{b}_{\mathbf{j}}\right)$ & $\mathbf{t}$ & $\mathbf{p}$ & $\mathbf{R}^{2}$ & ANOVA \\
Değişken & Değişken & 2,748 & 0,099 & 27,837 & $0,000^{* * *}$ & 0 & $\mathrm{~F}=92,034$ \\
\hline Örgütsel Vatandaşlık & Sabit & 0,290 & 0,030 & 9,593 & $0,000^{* * *}$ & 0,169 & $\mathrm{p}=0,000^{* * *}$ \\
Davranışı & İşlem Adaleti & & \\
\hline
\end{tabular}

${ }_{* * *}^{* *} p<0,001 \quad b_{j}:$ Katsayı $S\left(b_{j}\right):$ Standart Hata

Tablo 4'te de görüldüğü gibi, örgütsel adaletinin işlem adaleti boyutunun örgütsel vatandaşlık davranışı üzerindeki etkisine ilişkin gerçekleştirilen basit doğrusal regresyon modeli de anlamlı olup (F=84,529; $\mathrm{p}<0,001)$ matematiksel ifadesi aşağıda sunulmuştur: 
Örgütsel vatandaşlık davranışı $=2,748+0,290$ İA

Tablo 4'teki belirtme katsayısı $\left(\mathrm{R}^{2}=0,169\right)$, çalışanların örgütsel vatandaşlık davranışları üzerindeki değişimlerin \%16,9'unun algıladıkları işlem adaletinden kaynaklandığı göstermektedir. Bu durumda; “ $H_{2}$ : Otel çalışanların algıladıkları işlem adaletinin örgütsel vatandaşlık davranışları üzerinde anlamlı bir etkisi vardır" hipotezi desteklenmiştir.

Tablo 5. Etkileşim adaletinin örgütsel vatandaşlık davranışı üzerindeki etkisine yönelik gerçekleştirilen basit doğrusal regresyon analizi

\begin{tabular}{|c|c|c|c|c|c|c|c|}
\hline $\begin{array}{l}\text { Bağımlı } \\
\text { Değişken }\end{array}$ & $\begin{array}{l}\text { Bağımsız } \\
\text { Değişken }\end{array}$ & $\mathbf{b}_{\mathbf{j}}$ & $S\left(b_{j}\right)$ & $\mathbf{t}$ & $\mathbf{p}$ & $\mathbf{R}^{2}$ & ANOVA \\
\hline Örgütsel Vatandaşlık & Sabit & 2,526 & 0,100 & 25,314 & & \multirow{2}{*}{0,234} & \multirow{2}{*}{$\begin{array}{l}\mathrm{F}=138,808 \\
\mathrm{p}=0,000^{* * *}\end{array}$} \\
\hline Davranışı & Etkileşim Adaleti & 0,352 & 0,030 & 11,782 & $0,000^{* * *}$ & & \\
\hline
\end{tabular}

${ }_{* * *}^{*} p<0,001 \quad b_{j}:$ Katsayl $S\left(b_{j}\right):$ Standart Hata

Örgütsel adaletin etkileşim adaleti boyutu, örgütsel vatandaşlık davranışı ile ilişkisi diğer boyutlara nazaran daha yüksek olan boyuttur. Buna göre söz konusu ilişkinin kaynağına yönelik gerçekleştirilen basit doğrusal regresyon modeli (Tablo 5) de $(\mathrm{F}=138,808 ; \mathrm{p}<0,001)$ anlamlıdır. Bağımlı değişken (örgütsel vatandaşlık davranışı) ile bağımsız değişken (etkileşim adaleti) arasındaki ilişkiye ait basit doğrusal regresyon modeli aşağıda verilmiştir:

Örgütsel vatandaşlık davranışı $=2,526+0,352 \mathrm{EA}$

Tablo 5 'teki belirtme katsayısı $\left(\mathrm{R}^{2}=0,234\right)$ çalışanların örgütsel vatandaşlık davranışları üzerindeki değişimlerin \%23,4'ünün algıladıkları etkileşim adaletinden kaynaklandığını göstermektedir. Bu durumda; "H3: Otel çalışanların algıladıkları etkileşim adaletinin örgütsel vatandaşlık davranışları üzerinde anlamlı bir etkisi vardır" hipotezi desteklenmiştir.

Tablo 6: Örgütsel adaletin örgütsel vatandaşlık davranışı üzerindeki etkisine yönelik gerçekleştirilen basit doğrusal regresyon analizi

\begin{tabular}{llcccccc}
\hline $\begin{array}{l}\text { Bağımlı } \\
\text { Değişken }\end{array}$ & $\begin{array}{l}\text { Bağımsız } \\
\text { Değişken }\end{array}$ & $\mathbf{b}_{\mathbf{j}}$ & $\mathbf{S}\left(\mathbf{b}_{\mathbf{j}}\right)$ & $\mathbf{t}$ & $\mathbf{p}$ & $\mathbf{R}^{2}$ & ANOVA \\
\hline Örgütsel Vatandaşlık & Sabit & 2,476 & 0,105 & 23,599 & $0,000^{* * *}$ & 0 & $\mathrm{~F}=135,520$ \\
Davranışı & Örgütsel Adalet & 0,378 & 0,032 & 11,641 & $0,000^{* * *}$ & 0,230 & $\mathrm{p}=0,000^{* * *}$ \\
\hline
\end{tabular}

${ }_{* * *}^{*} p<0,001, b_{j}:$ Katsayı $S\left(b_{j}\right):$ Standart Hata

Örgütsel adaletin boyutlarının örgütsel vatandaşlık davranışına etkilerine ilişkin gerçekleştirilen basit doğrusal regresyon modellerinin yanı sıra, söz konusu etkiye bütün olarak bakabilmek için kurulan dördüncü hipotez de basit doğrusal regresyon analizi ile test edilmiş ve Tablo 6'da sunulmuştur. Tablo 6, örgütsel adaletinin örgütsel vatandaşlık davranışı üzerindeki etkisine ilişkin gerçekleştirilen basit doğrusal regresyon modelinin anlamlı olduğunu göstermektedir. ( $F=135,520 ; p<0,001$ ). Bağımlı değişken (örgütsel vatandaşlık davranışı) ile bağımsız değişken (örgütsel adalet) arasındaki ilişkiye ait basit doğrusal regresyon modeli aşağıda verilmiştir:

Örgütsel vatandaşlık davranışı $=2,476+0,378$ ÖA

Ayrıca Tablo 6'daki belirtme katsayısı $\left(\mathrm{R}^{2}=0,230\right)$ çalışanların örgütsel vatandaşlık davranışları üzerindeki değişimlerin \%23'ünün algıladıkları örgütsel adaletten kaynaklandığı anlaşılmaktadır. Bu durumda; " $H_{4}$ : Otel çalışanların algıladıkları örgütsel adaletin örgütsel vatandaşlık davranışları üzerinde anlamlı bir etkisi vardır" hipotezi desteklenmiştir.

\section{SONUÇ ve TARTIŞMA}

Otel çalışanlarının algıladıkları örgütsel adaletin örgütsel vatandaşlık davranışları üzerindeki etkisinin belirlenmesi amacıyla yapılan bu araştırma sonuçları, çalışanların örgütsel vatandaşlık davranışlarındaki 
değişimlerinin \%23'ünün algılanan örgütsel adaletten kaynaklandığını göstermektedir. Örgütsel adaletin boyutlarına göre değerlendirme yapıldığında, özellikle etkileşim adaleti boyutunun örgütsel vatandaşlık davranışına en fazla etki eden örgütsel adalet boyutu olduğu tespit edilmiştir. Yapılan basit doğrusal regresyon analizi, otel çalışanlarının örgütsel vatandaşlık davranışlarındaki değişimlerin \%23'4'ünün etkileşim adaletinden kaynaklandığına işaret etmektedir. Örgütsel adaletin diğer bir boyutu olan işlem adaleti de otel çalışanlarının örgütsel vatandaşlık davranışlarının \%16,9'unun kaynağını oluşturmaktadır. Dağıtım adaleti ise işlem adaletine yakın bir oranda $(\% 15,7)$ örgütsel vatandaşlık davranışına yön vermektedir.

Örgütsel adalet ve boyutlarının örgütsel vatandaşlık davranışı üzerindeki etkisine yönelik ortaya çıan sonuçlar, ilgili alanyazındaki çalışmalarla (Chan ve Lai, 2017; Chou vd., 2013; Deluga, 1995; Eskew, 1993; Farh vd., 1990; Greenberg, 1993; İşbaşı, 2000; Kim vd., 2009; Lim ve Loosemore, 2017; Moorman, 1991; Moorman vd., 1998; Olkonnen ve Lipponen, 2005; Organ, 1988; Organ ve Konovsky, 1989; Özduran ve Tanova, 2017; Schappe, 1998; Smith vd., 1983; Tansky; 1993) örtüşmektedir. Aynı zamanda daha önce de ifade edildiği gibi, sosyal değişim ve eşitlik kuramları, söz konusu etkiyi açıklayabilmektedir.

Bu araştırmada özellikle üzerinde durulması gereken sonuçlardan biri, örgütsel vatandaşlık davranışındaki değişimlerde en fazla etkileşim adaleti boyutunun etkisinin bulunmasıdır. Emek yoğun özelliği ön plana çıkan otelcilik sektöründe, örgüt içindeki iletişimin kalitesinin ve adilliğinin ne derece önemli olduğu bu araştırma sonuçları ile de ortaya konulmuştur. Özellikle etkileşim adaletinin örgütsel vatandaşlık davranışına en fazla yön veren boyut olması sonucu, otelcilik ve genel olarak turizm sektöründe çalışanların ekonomik beklentilerinin yanında, sosyal beklentilerinin ön plana çıktığını da göstermektedir. Otel yöneticilerinin işletmelerine katkı sağlayacak davranışları çalışanlarından beklerken, adil etkileşimin, adil işlemlerin ve adil dağıtımın hâkim olduğu çalışma ortamını hazırlaması gerektiği açıktır.

Etkileşim adaletinin sağlanması, diğer adalet türlerine nazaran daha alt seviye yöneticilerden başlamaktadır. Örneğin; dağıtım adaleti kapsamında kazanımların paylaştırılmasına yönelik kararlar örgütsel politikalarla ilişkili olabildiğinden, üst yönetimin kararları çerçevesinde değerlendirilebilir. Ancak etkileşim adaleti başta olmak üzere işlem adaleti, dağıtım adaletine göre daha kolay uygulanabilir nitelik taşımaktadır. Bu yüzden ara kademe yöneticilerin çalışanlara davranış biçimleri, örgütte adalet ikliminin sağlanmasında önemli belirleyici olarak değerlendirilmelidir. Daha önce de belirtildiği gibi yüz yüze hizmet sunulan otelcilik sektöründe adil etkileşim algılayan çalışanların gerek motivasyonları gerekse işlerine ve müşterilerine yaklaşım biçimleri farklı olacaktır. Bu durumda, turizm sektörü için gelecekte yapılacak araştırmalarda, örgütsel adaletin örgütsel vatandaşlık davranışındaki etkisinde liderlik davranışlarının aracilık rolünün incelenmesi gerektiği önerilebilir.

$\mathrm{Bu}$ araştırmanın verileri Kemer Bölgesi'ndeki beş yıldızlı otel işletmelerinde çalışanlardan elde edildiğinden, sayfiye otel çalışanları için çıkarım yapmayı sağlasa da şehir otelciliğini temsil etmeyecektir. Benzer çalışmaların farklı amaçlarla hizmet sunan şehir otellerindeki çalışanlar üzerinde de gerçekleştirilmesi, otelcilik sektöründe örgütsel adaletin örgütsel vatandaşlık davranışı üzerindeki etkisinin genellenebilmesi açısından önem taşımaktadır.

\section{KAYNAKÇA}

Adams, J.S. (1965). Inequity in social exchange. Advances in Experimental Social Psychology, 2, 267-299. 
Albrecht, S.L. and Travaglione, T. (2003). Trust in public sector senior management. International Journal of Human Resource Management, 14, 1-17.

Alexander, S. and Ruderman, M. (1987). The role of procedural and distributive justice in organizational behavior. Social Justice Research, 1, 177-198.

Aryee, S., Budhwar, P.S. and Chen, Z.X. (2002). Trust as a mediator of the relationship between organizational justice and work outcomes: Test of a social exchange model. Journal of Organizational Behavior, 23, 267-285.

Ay, G. and Koç, H. (2014). Örgütsel adalet algısı ile örgütsel bağlılık düzeyi arasındaki ilişkinin belirlenmesi: Öğretmenler üzerinde bir inceleme. İşletme Araştırmaları Dergisi, 6 (2), 67-90.

Basım, H.N. and Şeşen, H. (2006). Örgütsel vatandaşlık davranışı ölçeği uyarlama ve karşılaştırma çalışması. Ankara Üniversitesi Siyasi Bilimler Fakültesi Dergisi, 61 (4), 83-102.

Bateman, T.S. and Organ, D.W. (1983). Job satisfaction and the good soldier: The relationship between effect and employee citizenship. Academy of Management Journal, 26 (4), 587-595.

Begley, T.M., Lee, C. and Hui, C. (2006). Organizational level as a moderator of the relationship between justice perceptions and work-related reactions. Journal of Organizational Behaviour, 27, 705-721

Bies, R.J. (2001). Interactional (in)justice: The sacred and the profane. Greenberg, J. and Cropanzano, R. (Ed.), Advances in organizational justice, California: Stanford University Press, 89-118.

Blakely, G.L. andrews, M.C. and Moorman, R.H. (2005). The moderating effects of equity sensitivity on the relationship between organizational justice and organizational citizenship behaviors. Journal of Business and Psychology, 20 (2), 259-273.

Blau, P. (1964). Exchange and power in social life. New York: Wiley.

Borman, W. C. and Motowidlo. S. J. (1997). Introduction: Organizational Citizenship Behavior and Contextual Performance. Human Performance, 10, 67-69.

Brashear, T.G., Brooks, C.M. and Boles, J.S. (2004). Distributive and procedural justice in a sales force context: Scale development and validation. Journal of Business Research, 57, 86-93.

Camerman, J., Cropanzano, R. and Vandenberghe, C. (2007). The benefits of justice for temporary workers. Group and Organization Management, 32 (2), 176-207.

Chan, S.H.J. and Lai, H.Y.I. (2017). Understanding the link between communication satisfaction, perceived justice and organizational citizenship behavior. Journal of Business Research, 70, 214-223.

Choi, S. (2011). Organizational justice and employee work attitudes: the federal case. The American Review of Public Administration, 41 (2), 185-204.

Chou, T.-Y., Chou, S.-T., Jiang, J.J. and Klein, G. (2013). The organizational citizenship behavior of IS personnel: Does organizational justice matter? Information and Management, 50, 105-111.

Cohen, A. (2006). The relationship between multiple commitments and organizational citizenship behavior in arab and jewish culture. Journal of Vocational Behavior, 69, 105-118.

Cohen, R.L. (1987). Distributive justice: Theory and research. Social Justice Research, 1, 19-40.

Cropanzano, R. and Greenberg, J. (1997). Progress in organizational justice: Tunneling through the maze. Cooper, C.L. and Robertson, I.T. (Ed.), International Review of Industrial and Organizational Psyghology, 12, New York: John Wiley and Sons, 317-372.

Cropanzano, R. and Wright, T.A. (2003). Procedural justice and organizational staffing: A tale of two paradigms. Human Resource Management Review, 13 (1), 7-39.

Cropanzano, R., Byrne, Z.S.D. and Bobocel, R. (2001). Moral virtues, fairness heuristics, sosial entities and other denizens of organizational justice. Journal of Vocational Behavior, 58, 164-209.

Cropanzano, R. , Rupp, D.E. and Byrn, Z.S. (2003). The relationship of emotional exhaustion to work attitudes, job performanceand organizational citizenship behaviors. Journal Of Applied Phsychology, 88 (1), 160-169.

DeConinck, J.B. (2010). The effect of organizational justice, perceived organizational supportand perceived supervisor support on marketing employees' level of trust. Journal of Business Research, 63 (12), 1349-1355. 
Deluga, R.J. (1995). The relation between trust in the supervisor and subordinate organizational citizenship behaviors. Military Psychology, 7 (1), 1-16.

Dick, R.V., Knippenberg, D.V., Kerschreiter, R., Hertel, G. and Wieseke, J. (2008). Interactive effects of group and organizational identification on job satisfaction and extra-role behavior. Journal of Vocational Behavior, 72, 388-399.

Eskew, D.E. (1993). The role of organizational justice in organizational citizenship behavior. Employee Responsibilities and Rights Journal, 6 (3), 185-194.

Farh, J.L., Podsakoff, P.M. and Organ, D.W. (1990). Accounting for organizational citizenship behavior: Leader fairness and task scope versus satisfaction. Journal of Management, 16 (4), 705-721.

Folger, R. and Konovsky, M.A. (1989). Effect of procedural and distributive justice on reactions to pay raise decisions. Academy of Management Journal, 32 (1), 115-130.

Greenberg, J. (2004). Stress fairness to fare no stress: Managing workplace stress by promoting organizational justice. Organizational Dynamics, 33 (4), 352-365.

Greenberg, J. (1993). Justice and organizational citizenship: A commentary on the state of the science. Employee Responsibilities and Rights Journal, 6 (3), 249-256.

Greenberg, J. (1990). Organizational justice: Yesterday, today and tomorrow. Journal of Management, 16 (2), $399-432$.

Greenberg, J. and Baron, R.A. (2000). Behavior in Organizations (Seventh Edition), New Jersey: Prentice Hall.

Homans, G.C. (1958). Social behavior as exchange. American Journal of Sociology, 63 (6), 597-606.

Hon, A.H.Y. and Lu, L. (2010). The mediating role of trust between expatriate procedural justice and employee outcomes in Chinese hotel industry. International Journal of Hospitality Management, 29, 669-676.

Hubbell, A.P. and Chory-Assad, R.M. (2005) Motivating factors: Perceptions of justice and their relationship with managerial and organizational trust. Communication Studies, 56 (1), 47-70.

İşbaşı, J.Ö. (2000). Çalışanların yöneticilerine duydukları güvenin ve örgütsel adalete ilişkin algılamalarının örgütsel vatandaşlık davranışının oluşumundaki rolü: Bir turizm örgütünde uygulama. Yüksek lisans tezi, Akdeniz Üniversitesi Sosyal Bilimler Enstitüsü, Antalya.

Jahangir, N., Akbar, M. and Begum, N. (2006). The role of social power, procedural justice, organizational commitmentand job satisfaction to engerder organizational citizenship behavior. ABAC Journal, 26 (3), 21-36.

Keleş, Y. and Pelit, E. (2009). Otel işletmesi işgörenlerinin örgütsel vatandaşlık davranışları: İstanbul'daki beş yıldızlı otel işletmelerinde bir araştırma. Ekonomik ve Sosyal Araştırmalar Dergisi, 5 (2), 24-45.

Keleş, Y. and Tuna, M. (2016). Örgütsel adaletin duygusal emek üzerindeki etkisi: Antalya'daki beş yıldızlı otel işletmelerinde bir araştırma. İşletme Araştırmaları Dergisi, 8 (2), 376-406.

Kidder, D.L. (2002). The influence of gender on the performance of organizational citizenship behaviors. Journal of Management, 28 (5), 629-648.

Kim, W., Ok, C. and Lee, M.J. (2009). Antecedents of service employees' organizational citizenship behaviors in full-service restaurants in Korea. Cornell Hospitality Quarterly, 50 (2), 180-197.

Konovsky, M.A. (2000). Understanding procedural justice and its impact on business organizations. Journal of Management, 26 (3), 489-511.

Kwak, A. (2006). The relationships of organizational injustice with employee burnout and counterproductive work behaviors: equity sensitivity as a moderator. Doctoral dissertation, Central Michigan University, Michigan.

Lambert, E. (2003). The impact of organizational justice on correctional staff. Journal of Criminal Justice, 31, $155-168$.

Lee, C. and Farh, J-L. (1999). The effects of gender in organizational justice perceptions. Journal of Organizational Behaviour, 20, 133-143.

Lim, B.T.H. and Loosemore, M. (2017). The effect of inter-organizational justice perceptions on organizational citizenship behaviors in construction projects. International Journal of Project Management, $35,95-106$ 
Lowe, R.H. and Vodanowich, S.J. (1995). A field study of distributive and procedural justice as predictors of satisfaction and organizational commitment. Journal of Bussiness and Psychology, 10 (1), 99-114.

Martin, C.L. and Bennett, N. (1996). The role of justice judgments in explaining the relationship between job satisfaction and organizational commitment. Group and Organizational Management, 21 (1), 84-104.

Masterson, S.S., Lewis, K. Goldman, B.M. and Taylor, M.S. (2000). Integrating justice and social exchange: The differing effects of fair procedures and treatment on work relationships. Academy of Management Journal, 43, 738-749.

McFarlin, D.B. and Sweeney, P.D. (1992). Distributive and procedural justice as predictors of satisfaction with personal and organizational outcomes. Academy of Management Journal, 35 (3), 626-637.

Miles, D.E., Borman, W.E., Spector, P.E. and Fox, S. (2002). Building an integrative model of extra role work behaviors: A comparison of counterproductive work behavior with organizational citizenship behavior. International Journal of Selection and Assessment, 10 (1/2), 51-57.

Moorman, R.H. (1991). Relationship between organizational justice and organizational citizenship behaviors: Do fairness perceptions influence employee citizenship? Journal of Applied Psychology, 76 (6), 845-855.

Moorman, R.H., Blakely, G.L. and Niehoff, B.P. (1998). Does perceived organizational support mediate the relationship between procedural justice and organizational citizenship behavior? Academy of Management Journal, 41 (3), 351-357.

Moorman, R.H., Niehoff, B.P. and Organ, D.W. (1993). Treating employees fairly and organizational citizenship behavior: Sorting the effects of job satisfaction, organizational commitment and procedural justice. Employee Responsibilities and Rights Journal, 6 (3), 209-225.

Motowidlo, S. J. (2000). Some basic issues related to contextual performance and organizational citizenship behavior in human resource management. Human Resource Management Review, 10 (1), 115-126.

Niehoff, B.P. and Moorman, R. H. (1993). Justice as a mediator of the relationship between methods of monitoring and organizational citizenship behavior. Academy of Management Journal, 36 (3), 527-556.

Olkonen, M.E. and Lipponen, J. (2006). Relationships between organizational justice, identification with organization and work unitand group-related outcomes. Organizational Behavior and Human Decision Processes, 100 (2), 202-215.

Organ, D.W. (1988). O.C.B.: The good soldier syndrome. Lexington: Lexington Book.

Organ, D.W. and Konovsky, M. (1989). Cognitive versus affective determinants of organizational citizenship behavior. Journal of Applied Psychology, (74) 1, 157-164.

Özduran, A. and Tanova, C. (2017). Coaching and employee organizational citizenship behaviours: The role of procedural justice climate. International Journal of Hospitality Management, 60, 58-66.

Pelit, E. and Bozdoğan, İ. (2014). Çalışanların örgütsel adalet algılamalarının tükenmişlik düzeyleri üzerindeki etkisi: Kemer'deki beş yıldızlı otel işletmelerinde bir uygulama. Işsletme Araştırmaları Dergisi, $6(2), 37-66$.

Pillai, R., Schriesheim C.A. and Williams, E.S. (1999). Fairness perceptions and trust as mediators for transformational and transactional leadership: A two-sample study. Journal of Management, 25 (6), 897933.

Podsakoff, P.M., Ahearne, M. and Mackenzie, S.B. (1997). Organizational citizenship behavior and the quantity and quality of work group performance. Journal of Applied Psychology, 82 (2), 262-270.

Podsakoff, P.M. and Mackenzie, S.B. (1994). Organizational citizenship behaviours and sales unit effectiveness. Journal of Marketing Research, 31 (3), 351-363.

Podsakoff, P.M., Mackenzie, S.B., Moorman, R.H. and Fetter, R. (1990). Transformational Leader Behaviors and Their Effects on Followers' Trust in Leader, Satisfaction and Organizational Citizenship Behaviors. The Leadership Quarterly, 1 (2), 107-142.

Podsakoff, P.M., Mackenzie, S.B., Paine, J.B. and Bachrach, D.G. (2000). Organizational citizenship behaviors: a critical review of the theoretical and empirical literature and suggestions for future research. Journal of Management, 26 (3), 513-563. 
Ramamoorthy, N. and Flood, P.C. (2004). Gender and employee attitudes: The role of orgaznizational justice perceptions. British Journal of Management, 15, 247-258.

Scandura, T.A. (1999). Rethinking leader-member exchange: An organizational justice perspective. Leadership Quarterly, 10 (1), 25-40.

Schappe, S.P. (1998). The influence of job satisfaction, organizational commitment and fairness perceptions on organizational citizenship behavior. The Journal of Psychology, 132 (3), 277-290.

Schnake, M.E. and Dumler, M.P. (2003). Levels of measurement and analysis issues in organizational citizenship behavior research. Journal of Occupational and Organizational Psychology, 76, 283-301.

Skarlicki, D.P. and Folger, R. (1997). Retaliation in the workplace: The roles of distributive, procedural and interactional justice. Journal of Applied Psychology, 82 (3), 434-443.

Skarlicki, D.P., Folger, R. and Tesluk, P. (1999). Personality as a moderator in the relationship between fairness and retaliation. The Academy of Management Journal, 42 (1), 100-108.

Smith, C. A., Organ, D.W. and Near, J.P. (1983). Organizational citizenship behavior: Its nature and antecedents. Journal of Applied Psychology, 68 (4), 653-663

Somech, A. and Ron, I. (2007). Promoting organizational citizenship behavior in schools: The impact of individual and organizational characteristics. Educational Administration Quarterly, 43 (1), 38-66.

Tang, T.L-P. and Baldwin, L.J. (1996). Distributive and procedural justice as related to satisfaction and commitment. Advanced Management Journal, 61 (3), 25-31.

Tansky, J.W. (1993). Justice and organizational citizenship behavior: What is the relationship? Employee Responsibilities and Right Journal, 6 (3), 195-207.

Taxman, F.S. and Gordon, J.A. (2009). Do fairness and equity matter? An examination of organizational justice among correctional officers in adult prisons. Criminal Justice and Bahavior, 36 (7), 695-711.

TDK (2019). Büyük Türkçe Sözlük. http://www.tdk.gov.tr/ (Erişim tarihi: 03.01.2019)

Tyler, T.R. (1988). What is procedural justice? Criteria used by citzens to assess the fairness of legal procedures. Law and Society Review, 22 (1), 103-136.

Van Dyne, L., Graham, J.W. and Dienesch, R.M. (1994). Organizational citizenship behavior: Construct redefinition, measurement and validation. Academy Of Management Journal, 37 (4), 765-802.

VanYperen, N.W., Hagedoorn, M., Zweers, M. and Postma, S. (2000). Injustice and employees' destructive responses: The mediating role of state negative affect. Social Justice Research, 13 (3), 291-312.

Vey, M.E. and Campbell, J.P. (2004). In-role or extra-role organizational citizenship behavior: Which are we measuring? Human Performance, 17 (1), 119-135.

Williams, L.J. and Anderson, S.E. (1991). Job satisfaction and organizational commitment as predictors of organizational citizenship and in-role behaviors. Journal of Management, 17, 601-617.

Williams, S. and Shiaw, W.T. (1999). Mood and organizational citizenship behavior: The effects of positive affect on employee organizational citizenship behavior intentions. The Journal of Psychology, 133 (6), 656668.

Yang, J., Mossholder, K.W. and Peng, T.K. (2009). Supervisory procedural justice effects: The mediating roles of cognitive and affective trust. The Leadership Quarterly, 20, 143-154.

Yıldırım, F. (2003). Çalışma yaşamında örgütsel bağlılık ile örgütsel adalet: Örgüt temelli özsaygı ve bazı kişisel ve örgütsel değişkenlerin ilişkisi. Mülkiye, 27 (239), 371-402. 